\title{
Improvement of Water Solubility of Josamycin by Inclusion Complex with $\gamma$-Cyclodextrin
}

\author{
J. El Harti, ${ }^{1}$ Y. Cherrah, ${ }^{2,3}$ and A. Bouklouze ${ }^{2,3}$ \\ ${ }^{1}$ Medicinal Chemistry Research Team, Faculty of Medicine and Pharmacy, University Mohammed V, Souissi, BP 6203, Rabat, Morocco \\ ${ }^{2}$ Pharmaceutical and Toxicological analysis Research Team, Laboratory of Pharmacology and Toxicology, Faculty of Medicine and \\ Pharmacy, University Mohammed V, Souissi, BP 6203, Rabat, Morocco \\ ${ }^{3}$ Centre de Recherche en Epidémiologie Clinique et Essais thérapeutiques, Faculty of Medicine and Pharmacy, University Mohammed V, \\ Souissi, BP 6203, Rabat, Morocco
}

Correspondence should be addressed to A. Bouklouze, a.bouklouze@um5s.net.ma

Received 2 November 2011; Accepted 20 November 2011

Academic Editors: D. Heimler and V. Stefov

Copyright () 2012 J. El Harti et al. This is an open access article distributed under the Creative Commons Attribution License, which permits unrestricted use, distribution, and reproduction in any medium, provided the original work is properly cited.

Josamycin propionate (JMP) is an antibiotic belonging to the family of macrolide. According to the Biopharmaceutical Classification System (BCS), this compound can be classed in class II, low solubility and high permeability. In order to increase its apparent water solubility, inclusion complexation between Josamycin propionate and $\gamma$-cyclodextrin $(\gamma$-CD) was studied. UV spectrophotometric method was employed to investigate the phase-solubility profile and the stability constant of the complexation in aqueous medium. Solid state of the binary system prepared by coevaporation (in 50\%-50\% ethanol/water) has been characterized using powder X-ray diffraction (XRD) and Fourier transformation-infrared spectrometry (FTIR). These techniques indicate that JMP forms an association complex with $\gamma$-CD. The shift in the nuclear magnetic resonance spectroscopy $(1 \mathrm{H}$ NMR) confirms the existence of the inclusion complex. Also the results obtained showed an enhancement of the solubility in water of Josamycin propionate.

\section{Introduction}

Cyclodextrins (CDs) (Figure 1) are macrocyclic oligosaccharides constituted by 6,7 , or $8 \mathrm{D}$-glucose units forming $\alpha$-, $\beta$ - and $\gamma$-cyclodextrin, respectively. They have the property of forming inclusion complex with various quest molecules with suitable polarity and dimension because of their special molecular structure/hydrophobic internal cavity and hydrophilic external surface. The most probable binding involves the insertion of the lipophilic portion of the guest molecule into the cavity of the host and displacement of the water molecules located inside the cavity [1-3].

The Complexation with cyclodextrins has been widely used to improve the solubility, dissolution rate, stability, bioavailability of poorly water-soluble drugs, and elimination of undesired properties of drug, such as unpleasant odor and taste [4-9]. In our knowledge no study has been reported in the literature which interested to improve solubility of Josamycin propionate.
Josamycin propionate (JMP) (Figure 2) is a macrolide antibiotic, produced by Streptomyces narbonensis vary $[10$ 12], characterized by a large lactone ring, a ketone group and a glycosidically linked amino sugar attached to nucleus which explains the basicity of this antibiotic [13]. According to the Biopharmaceutical Classification System (BCS), this compound can be classed in class II, poorly soluble in aqueous medium but permeable $[14,15]$.

The aim of this study was to prepare and to characterize inclusion complexes of Josamycin propionate in $\gamma$-CD, to provide a way to increase their aqueous solubility. Phasesolubility diagram was used to evaluate the solubility of this macrolide and to determine its stability constant of the complex. The characterization of the binary mixtures as performed using differential scanning calorimetry (DSC), powder X-ray diffractometry, and Fourier transformationinfrared spectrometry (FTIR). Finally, the shift in the nuclear magnetic resonance spectroscopy $\left({ }^{1} \mathrm{H}\right.$ NMR $)$ was performed to confirm the existence of the inclusion complex. 


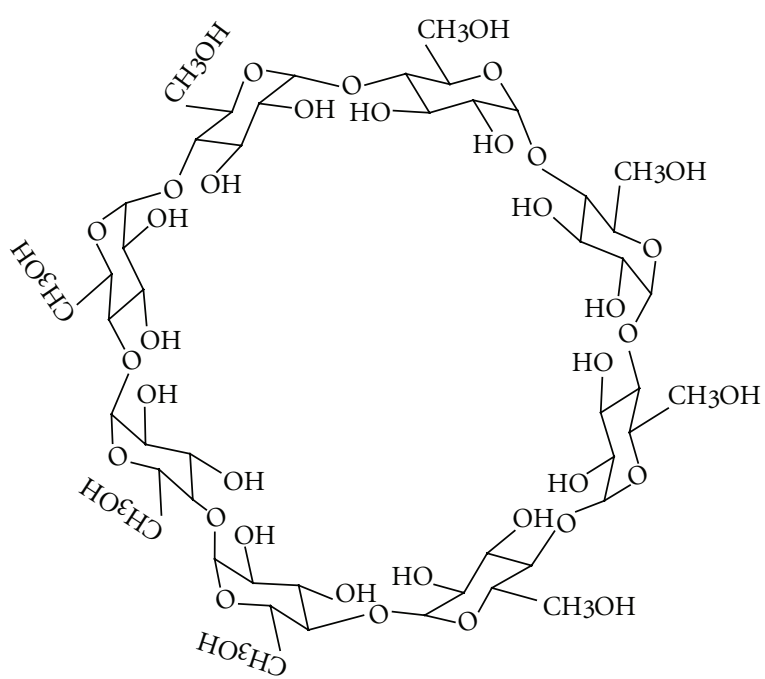

FIGURE 1: chemical structure of $\gamma$-cyclodextrin.

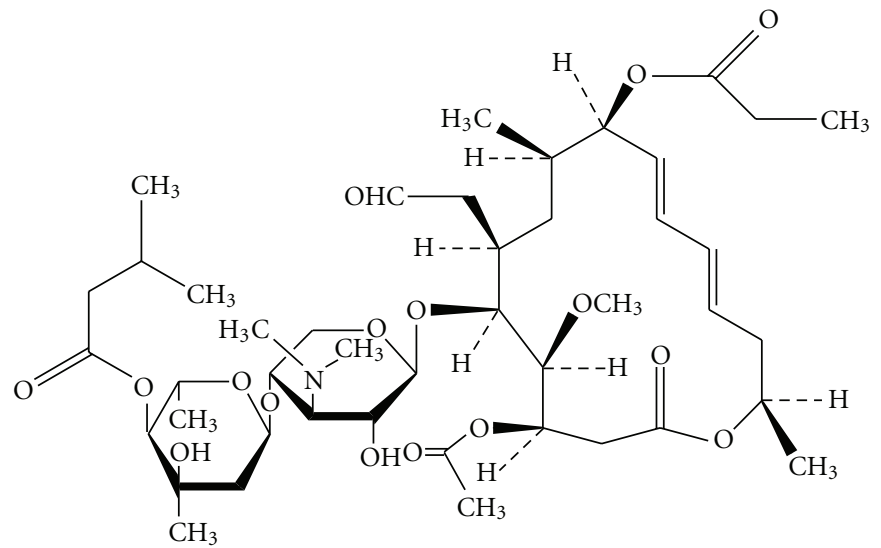

FIGURE 2: Chemical structure of Josamycin propionate.

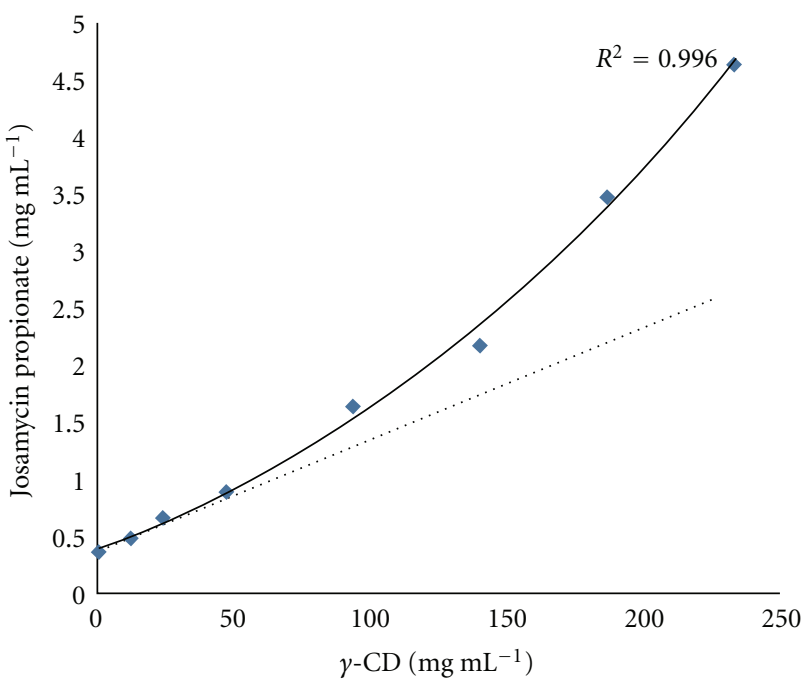

FIgURe 3: Phase-solubility diagrams for JMP with $\gamma$-CD at $27^{\circ} \mathrm{C}$. 


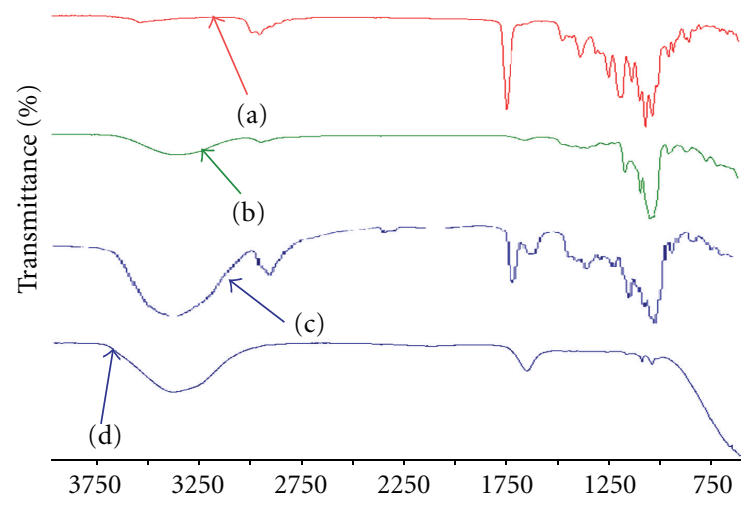

FIGURE 4: IR spectra of pure $\gamma$-CD (a), JMP (b), physical mixture (c), and co-evaporated product (d). \% transmittance versus wave number $\left(\mathrm{cm}^{-1}\right)$.

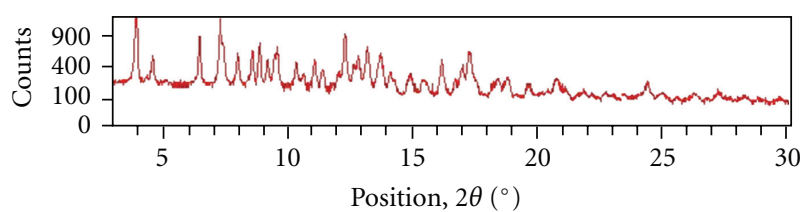

(a)

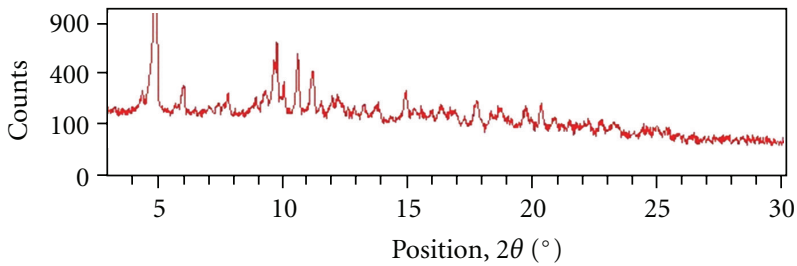

(c)

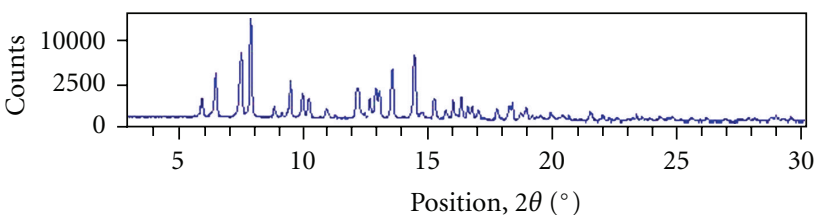

(b)

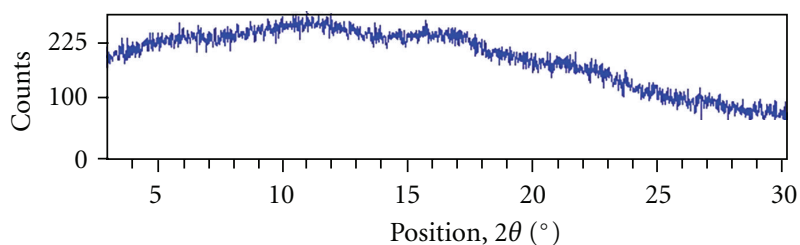

(d)

Figure 5: X-ray curves of pure $\gamma$-CD (a), JMP (b), physical mixture (c), and co-evaporated product (d).

\section{Materials and Methods}

2.1. Materials. Josamycin propionate (pharmaceutical grade) was obtained graciously from National Laboratory of Drug Control (Morocco). $\gamma$-cyclodextrin was purchased from Sigma; all other reagents were of analytical grade. Distilled water was used throughout the experiment.

2.2. Phase Solubility Studies. Phase solubility diagrams were obtained at room temperature $\left(27^{\circ} \mathrm{C}\right)$ in water. An excess amount of the guest molecule JMP (100 mg) was added to a series of $5 \mathrm{~mL}$ flasks each containing increasing quantities of $\gamma$-CD (ranging from 0 to $232 \mathrm{mg} / \mathrm{mL}$ ). The suspension was shaken for $72 \mathrm{~h}$, after the steady state was reached. A portion of the sample was appropriately diluted with methanol and analyzed by an UV spectrophotometric method at $232 \mathrm{~nm}$ to assess the concentration of the Josamycin propionate dissolved according to European Pharmacopeia [13]. The phase solubility was constructed by plotting the total dissolved JMP concentration against the total $\gamma$-CD concentration. The stability constant (Ks) of the complex was calculated from the slope of phase solubility diagram according to Higuchi and Connors equation:

$$
\mathrm{Ks}=\frac{\text { Slope }}{\mathrm{S} 0(1-\mathrm{Slope})}
$$

where $\mathrm{S} 0$ is the solubility of JMP in absence of $\gamma$-CD.

2.3. Preparation of Binary Mixtures. The complex of Josamycin propionate with $\gamma$-CD in $1: 1$ molar ratio was prepared by the coprecipitation method, by dissolving an appropriate amount of JMP $(x \mathrm{mg})$ and $\gamma$-CD $(y \mathrm{mg})$ in $25 \mathrm{~mL}$ of water ethanol (V/V). The solution was stirred for $10 \mathrm{~h}$ and the solvent was removed at $45^{\circ} \mathrm{C}$. The physical mixture (noncomplexed drug) was obtained by mixing an exactly weighed (1:1 molar ratio) amounts of JMP and $\gamma$ CD powders in mortar with continuous stirring for $10 \mathrm{~min}$.

2.4. Powder X-Ray Diffraction (XRD). XRD was used as another quantitative measure of crystallinity of JMP and developed to characterize the formation of the inclusion 


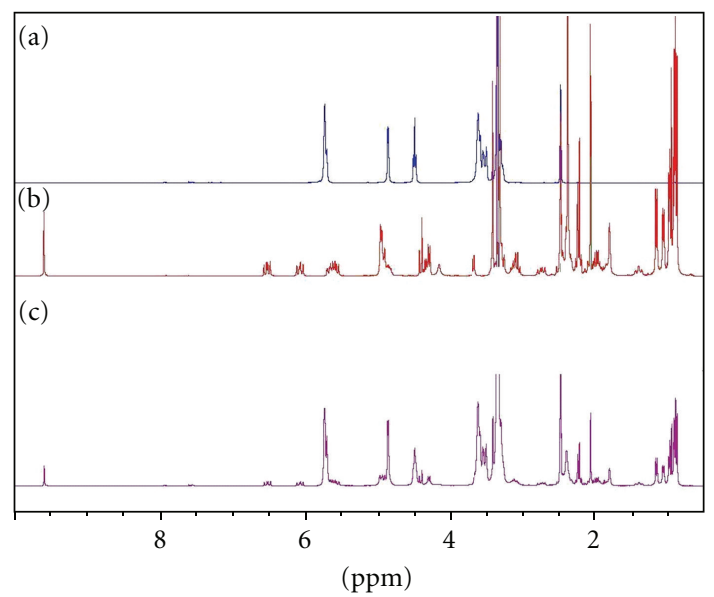

FIGURE 6: ${ }^{1} \mathrm{H}$ NMR spectra in DMSO- $\mathrm{d}_{6}$ of pure $\gamma$-CD (a), JMP (b), and co-evaporated product (c).

complexation. The powder X-ray diffraction patterns of JMP, $\gamma$-CD, physical mixture, and corresponding complex were recorded using an automatic powder diffractometer (Philips $\mathrm{X}^{\prime}$ Pert $\mathrm{PRO}$ ). X-ray patterns were obtained in the angular range of $5-50^{\circ} 2 \theta$, with $2 \mathrm{~s}$ fixed time for each $0.04^{\circ}$ step.

2.5. FTIR Spectroscopy. The IR spectra of pure materials, physical mixture and corresponding complex were measured, using an FTIR spectrophotometer (TANSOR 27 Bruker ATR) using $\mathrm{KBr}$ pelleting. The scans were executed at a resolution of $8 \mathrm{~cm}^{-1}$ from $4000 \mathrm{~cm}^{-1}$ to $500 \mathrm{~cm}^{-1}$.

2.6. ${ }^{1} H$ NMR Spectroscopy. The ${ }^{1} \mathrm{H}$ NMR spectra of the samples were recorded at $25^{\circ} \mathrm{C}$ using the NMR spectrometer (AVANCE 300 Bruker) employing DMSO- $\mathrm{d}_{6}$ as a solvent. The $\mathrm{H}^{1} \mathrm{NMR}$ chemical shift $(\Delta \delta)$ caused upon complexation were measured only for both $\mathrm{H}_{5}$ and $\mathrm{H}_{3}$ which are located inside the cyclodextrin cavity, to confirm the inclusion complex of JMP and calculated according to the following formula:

$$
\Delta \delta=\delta_{\text {complexed state }}-\delta_{\text {free state }}
$$

\section{Results and Discussion}

3.1. Solubility Studies. The phase solubility diagram of JMP$\gamma$-CD system was reported in (Figure 3 ). The solubility of JMP increases linearly as a function of $\gamma$-CD concentration $(0-250 \mathrm{mg} / \mathrm{mL})$. And the solubility curve can be classified as $A_{P}$ type [2], according to the Higuchi and Connors classification. When there is a linear increase in guest molecule solubility with increase in cyclodextrin concentration, a cyclodextrin complex of the guest results from $1: 2 \mathrm{~mol} / \mathrm{mol}$ interactions. According with this theory, it is possible to assume that $1: 2 \mathrm{~mol} / \mathrm{mol} \mathrm{JMP} / \gamma$-CD inclusion compound was formed. The solubility calculated for JMP in water was $0.35 \mathrm{mg} / \mathrm{mL}$ at $27^{\circ} \mathrm{C}$; this solubility increased linearly giving $4.60 \mathrm{mg} / \mathrm{mL}$ in the presence of $250 \mathrm{mg} / \mathrm{mL} \gamma$-CD. The stability constant value calculated was $3060 \mathrm{M}^{-1}$, also the larger constant observed indicate that JMP interact strongly with
$\gamma$-CD. Furthermore the correlation between the solubility of JMP and the concentration of $\gamma$-CD suggested that water soluble complex was formed [14-16].

3.2. IR Spectra Studies. Figure 4 shows the infrared spectra of $\gamma$-CD, JMP, physical mixture, and corresponding complex. JMP has a carbonyl band of $1600-1750 \mathrm{~cm}^{-1}$, may be due to a ring lactone $[17,18]$, in the spectrum of the physical mixture there is no change. Whereas in the IR spectrum of the corresponding complex there is a significance decrease was observed in its intensity. IR spectrum of JMP contains a band with shoulders $\left(3000-3500 \mathrm{~cm}^{-1}\right)$ due to hydrate form [19].

In the spectrum of $\gamma$-CD some bands in the range 1030$1160 \mathrm{~cm}^{-1}$ can be associated with the stretching frequency of primary and secondary $\mathrm{C}-\mathrm{OH}$ groups [20], those bands disappearance in the complex.

The intensity and shape of bands between 800$1500 \mathrm{~cm}^{-1}$ changed dramatically for the inclusion compound as compared to those for pure JMP, $\gamma$-CD, and physical mixture. Thus indicating that the vibrating and bending of the guest molecule (JMP) was restricted due to the formation of inclusion complex $[17,20,21]$.

3.3. X-Ray Diffraction Analysis. The XRD pattern of pure drug presented several diffraction peaks indicating the crystalline nature of the drug (Figure 5), the $\gamma$-CD also exhibited a typical crystalline diffraction pattern. Among the physical mixture showed several peaks attributable both to the crystalline drug and $\gamma$-CD. The coevaporated product showed a single very broad band in witch the diffraction peaks of drug and $\gamma$-CD disappeared. This phenomenon confirmed that an inclusion complex between drug and $\gamma$ $\mathrm{CD}$ was formed and which indicates the formation of a new crystalline phase [21-26].

3.4. HNMR Spectroscopy. Cyclodextrin has six identifiable protons in the NMR spectrum: protons $\mathrm{H}_{1}, \mathrm{H}_{2}, \mathrm{H}_{4}$ being at the outer surface of $\mathrm{CD}$, while protons $\mathrm{H}_{3}$ and $\mathrm{H}_{5}$ sit in the 


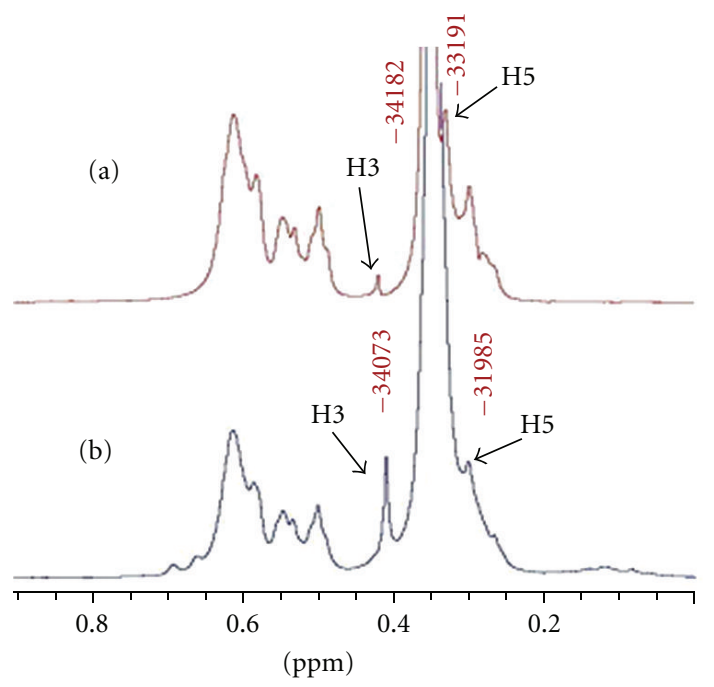

Figure 7: Partial ${ }^{1} \mathrm{H}$ NMR spectra in DMSO- $\mathrm{d}_{6}$ of pure $\gamma$-CD (a), and Co-evaporated product (b).

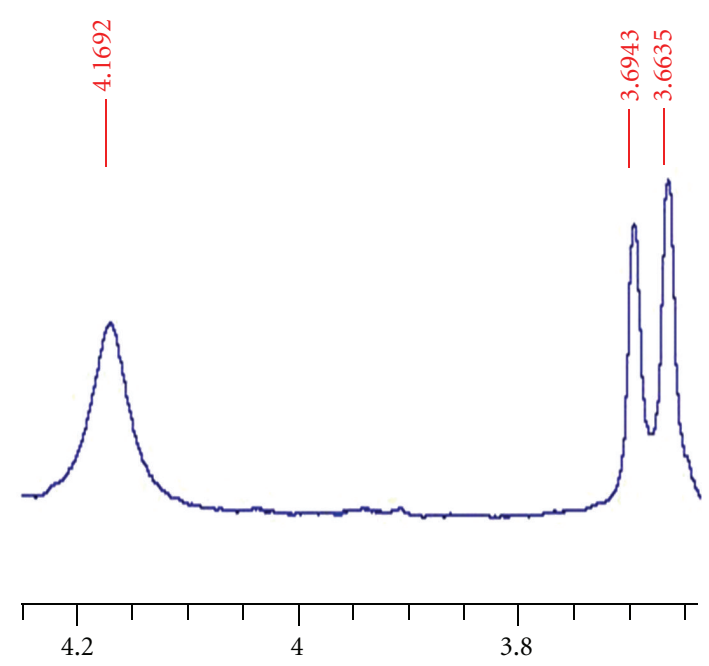

(a)

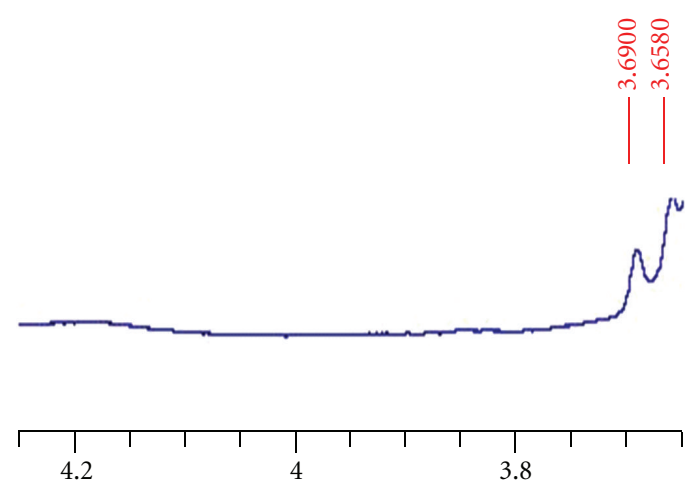

(b)

FIgURE 8: Partial ${ }^{1} \mathrm{H}$ NMR spectra in DMSO- $\mathrm{d}_{6}$ of pure JMP (a), and co-evaporated product (b).

cavity and are very important for the study of the interaction of guest molecules with cyclodextrins.

The NMR spectra (Figure 6) and the partial ${ }^{1} \mathrm{H}$ NMR spectra in DMSO- $\mathrm{d}_{6}$ of pure $\gamma$-CD and co-evaporated product (Figure 7) show that the inclusion of JMP into the $\gamma$-CD induces upfield changes in the ${ }^{1} \mathrm{H}$ NMR chemical shift values for both the protons $\mathrm{H} 3$ and $\mathrm{H} 5$ with $(\Delta \delta=$ $0.0306 \mathrm{ppm}$ and $\Delta \delta=0.0106 \mathrm{ppm}$ ), respectively. It is noteworthy that NMR allows clear distinction between inclusion and any other possible external interaction processes, with large effects observed on the proton located in the hydrophobic cavity (H3 and $\mathrm{H} 5$ ), clearly proving inclusion in aqueous medium. On the other hand, protons located on the outside experience no or very small shift $[27,28]$.

As shown in (Figure 7) and in the partial ${ }^{1} \mathrm{H}$ NMR spectra in DMSO- $\mathrm{d}_{6}$ of pure JMP and coevaporated product (Figure 8), the singlet peak at the value of the chemical shift of $4.16 \mathrm{ppm}$ which can be attributed to the methyl group belonging to the portion of the conjugated carbon chain of pure JMP disappears in the association complex.

However, it is probably that $\left(-\mathrm{CH}=\mathrm{CH}-\mathrm{CH}=\mathrm{CH}-\mathrm{CH}_{2}\right.$ $-\mathrm{CH}-\mathrm{CH} 3$ ) part of JMP structure, which is highly hydrophobic, was completely embedded inside the lipophilic core of $\gamma$-cyclodextrin.

\section{Conclusion}

The results of this study clearly evidence that the Josamycin propionate can be efficiently complexed with $\gamma$-cyclodextrin in a relatively high proportion forming an inclusion complex.

The properties of complex were characterized by phasesolubility techniques, X-ray diffraction, FTIR spectroscopy, and ${ }^{1} \mathrm{H}$ NMR spectroscopy. Thus, the pharmaceutical property of aqueous solubility of Josamycin propionate can be improved. 


\section{References}

[1] Y. Saito, H. Ueda, M. Abe, T. Sato, D. Sherril, and S. D. Christian, "Inclusion complexation of Triton X-100 with $\alpha-, \beta$ and $\gamma$-cyclodextrins," Colloids and Surfaces A, vol. 135, no. 13, pp. 103-108, 1998.

[2] E. M. M. Del Valle, "Cyclodextrins and their uses: a review," Process Biochemistry, vol. 39, no. 9, pp. 1033-1046, 2004.

[3] N. Li, Y. Zhang, Y. Wu, X. Xiong, and Y. Zhang, "Inclusion complex of trimethoprim with $\beta$-cyclodextrin," Journal of Pharmaceutical and Biomedical Analysis, vol. 39, no. 3-4, pp. 824-829, 2005.

[4] O. A. Soliman, K. Kimura, F. Hirayama et al., "Amorphous spironolactone-hydroxypropylated cyclodextrin complexes with superior dissolution and oral bioavailability," International Journal of Pharmaceutics, vol. 149, no. 1, pp. 7383, 1997.

[5] N. B. Naidu, K. P. R. Chowdary, K. V. R. Murthy, V. Satyanarayana, A. R. Hayman, and G. Becket, "Physicochemical characterization and dissolution properties of meloxicamcyclodextrin binary systems," Journal of Pharmaceutical and Biomedical Analysis, vol. 35, no. 1, pp. 75-86, 2004.

[6] S. Scalia, A. Molinari, A. Casolari, and A. Maldotti, "Complexation of the sunscreen agent, phenylbenzimidazole sulphonic acid with cyclodextrins: effect on stability and photo-induced free radical formation," European Journal of Pharmaceutical Sciences, vol. 22, no. 4, pp. 241-249, 2004.

[7] S. Tommasini, D. Raneri, R. Ficarra, M. L. Calabrò, R. Stancanelli, and P. Ficarra, "Improvement in solubility and dissolution rate of flavonoids by complexation with $\beta$-cyclodextrin," Journal of Pharmaceutical and Biomedical Analysis, vol. 35, no. 2, pp. 379-387, 2004.

[8] J. Veillaverde, J. Pérez-Martínez, C. Maqueda, J. M. Ginés, and E. Morillo, "Inclusion complexes of $\alpha$ - and $\gamma$-cyclodextrins and the herbecide norflurazon: I. Preparation and characerization II. Enhanced solubilisation and removal from soils," Chemosphere, vol. 60, pp. 656-664, 2005.

[9] K. Terao, D. Nakata, H. Fukumi et al., "Enhancement of oral bioavailability of coenzyme Q10 by complexation with $\gamma$ cyclodextrin in healthy adults," Nutrition Research, vol. 26, no. 10, pp. 503-508, 2006.

[10] G. Rondini, C. E. Cocuzza, M. Cianflone, A. Lanzafame, L. Santini, and R. Mattina, "Bacteriological and clinical efficacy of various antibiotics used in the treatment of streptococcal pharyngitis in Italy. An epidemiological study," International Journal of Antimicrobial Agents, vol. 18, no. 1, pp. 9-17, 2001.

[11] K. Kasahara, A. Nishikawa, F. Furukawa et al., "A chronic toxicity study of josamycin in F344 rats," Food and Chemical Toxicology, vol. 40, no. 7, pp. 1017-1022, 2002.

[12] R. Gattringer, R. Sauermann, H. Lagler et al., "Antimicrobial susceptibility and macrolide resistance genes in Streptococcus pyogenes collected in Austria and Hungary," International Journal of Antimicrobial Agents, vol. 24, no. 3, pp. 92-95, 2004.

[13] European Phrmacopeia 5.0 Josamycin propionate General notices (1) apply to all monographs and other texts 18611862.

[14] T. Loftsson, "Cyclodextrins and the biopharmaceutics classification system of drugs," Journal of Inclusion Phenomena, vol. 44, no. 1-4, pp. 63-67, 2002.

[15] M. E. Brewster and T. Loftsson, "Cyclodextrins as pharmaceutical solubilizers," Advanced Drug Delivery Reviews, vol. 59, no. 7, pp. 645-666, 2007.

[16] C. Anselmi, M. Centini, M. Ricci et al., "Analytical characterization of a ferulic acid/ $\gamma$-cyclodextrin inclusion complex,"
Journal of Pharmaceutical and Biomedical Analysis, vol. 40, no. 4, pp. 875-881, 2006.

[17] N. Sarisuta, M. Kumpugdee, B. W. Müller, and S. Puttipipatkhachorn, "Physico-chemical characterization of interactions between erythromycin and various film polymers," International Journal of Pharmaceutics, vol. 186, no. 2, pp. 109-118, 1999.

[18] R. Gandhi, O. Pillai, R. Thilagavathi, B. Gopalakrishnan, C. L. Kaul, and R. Panchagnula, "Characterization of azithromycin hydrates," European Journal of Pharmaceutical Sciences, vol. 16, no. 3, pp. 175-184, 2002.

[19] X. Wen, F. Tan, Z. Jing, and Z. Liu, "Preparation and study the $1: 2$ inclusion complex of carvedilol with $\beta$-cyclodextrin," Journal of Pharmaceutical and Biomedical Analysis, vol. 34, no. 3, pp. 517-523, 2004.

[20] L. Martín, A. León, M. A. Martín, B. del Castillo, and J. C. Menéndez, "Detection and charcterization of cyclodextrin complexes with $\beta$-carboline derivatives by spectroscopic techniques," Journal of Pharmaceutical and Biomedical Analysis, vol. 32, no. 4-5, pp. 991-1001, 2003.

[21] R. Ficarra, S. Tommasini, D. Raneri et al., "Study of flavonoids/ $\beta$-cyclodextrins inclusion complexes by NMR, FTIR, DSC, X-ray investigation," Journal of Pharmaceutical and Biomedical Analysis, vol. 29, no. 6, pp. 1005-1014, 2002.

[22] A. Zornoza, C. Martín, M. Sánchez, I. Vélaz, and A. Piquer, "Inclusion complexation of glisentide with $\alpha$-, $\beta$ - and $\gamma$-cyclodextrins," International Journal of Pharmaceutics, vol. 169, no. 2, pp. 239-244, 1998.

[23] M. D. Veiga and M. Merino, "Interactions of oxyphenbutazone with different cyclodextrins in aqueous medium and in the solid state," Journal of Pharmaceutical and Biomedical Analysis, vol. 28, no. 5, pp. 973-982, 2002.

[24] G. Zingone and F. Rubessa, "Preformulation study of the inclusion complex warfarin- $\beta$-cyclodextrin," International Journal of Pharmaceutics, vol. 291, no. 1-2, pp. 3-10, 2005.

[25] X. Wen, Z. Liu, T. Zhu, M. Zhu, K. Jiang, and Q. Huang, "Evidence for the 2:1 molecular recognition and inclusion behaviour between $\beta$ - and $\gamma$-cyclodextrins and cinchonine," Bioorganic Chemistry, vol. 32, no. 4, pp. 223-233, 2004.

[26] P. L. Dentuto, L. Catucci, P. Cosma et al., "Cyclodextrin/chlorophyll a complexes as supramolecular photosensitizers," Bioelectrochemistry, vol. 70, no. 1, pp. 39-43, 2007.

[27] S. Abrahmsén-Alami, E. Alami, J. Eastoe, and T. Cosgrove, "Interaction between a novel gemini surfactant and cyclodextrin: NMR and surface tension studies," Journal of Colloid and Interface Science, vol. 246, no. 1, pp. 191-202, 2002.

[28] W. Al-Soufi, P. R. Cabrer, A. Jover, R. M. Budal, and J. V. Tato, "Determination of second-order association constants by global analysis of $1 \mathrm{H}$ and 13C NMR chemical shifts. Application to the complexation of sodium fusidate and potassium helvolate by $\beta$ - and $\gamma$-cyclodextrin," Steroids, vol. 68 , no. 1 , pp. 43-53, 2003. 


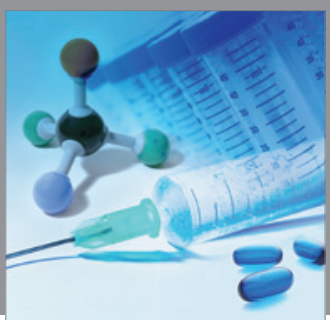

International Journal of

Medicinal Chemistry

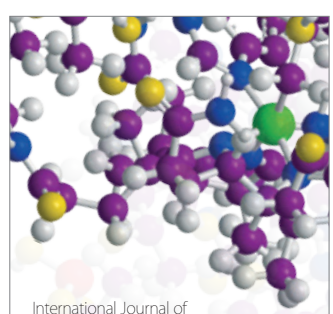

Carbohydrate Chemistry

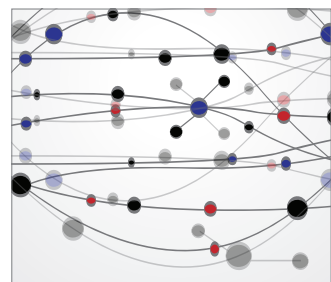

The Scientific World Journal
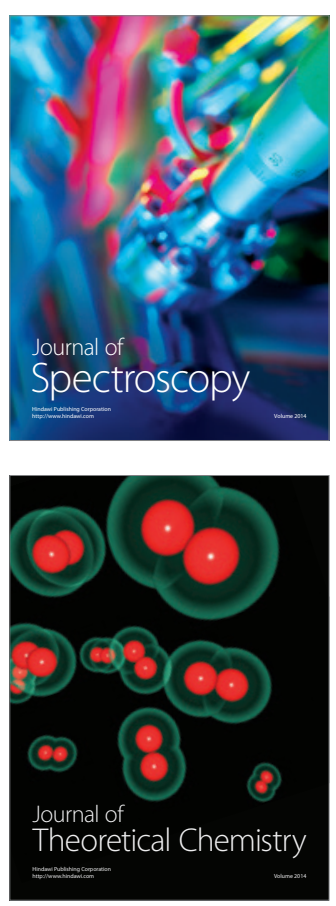
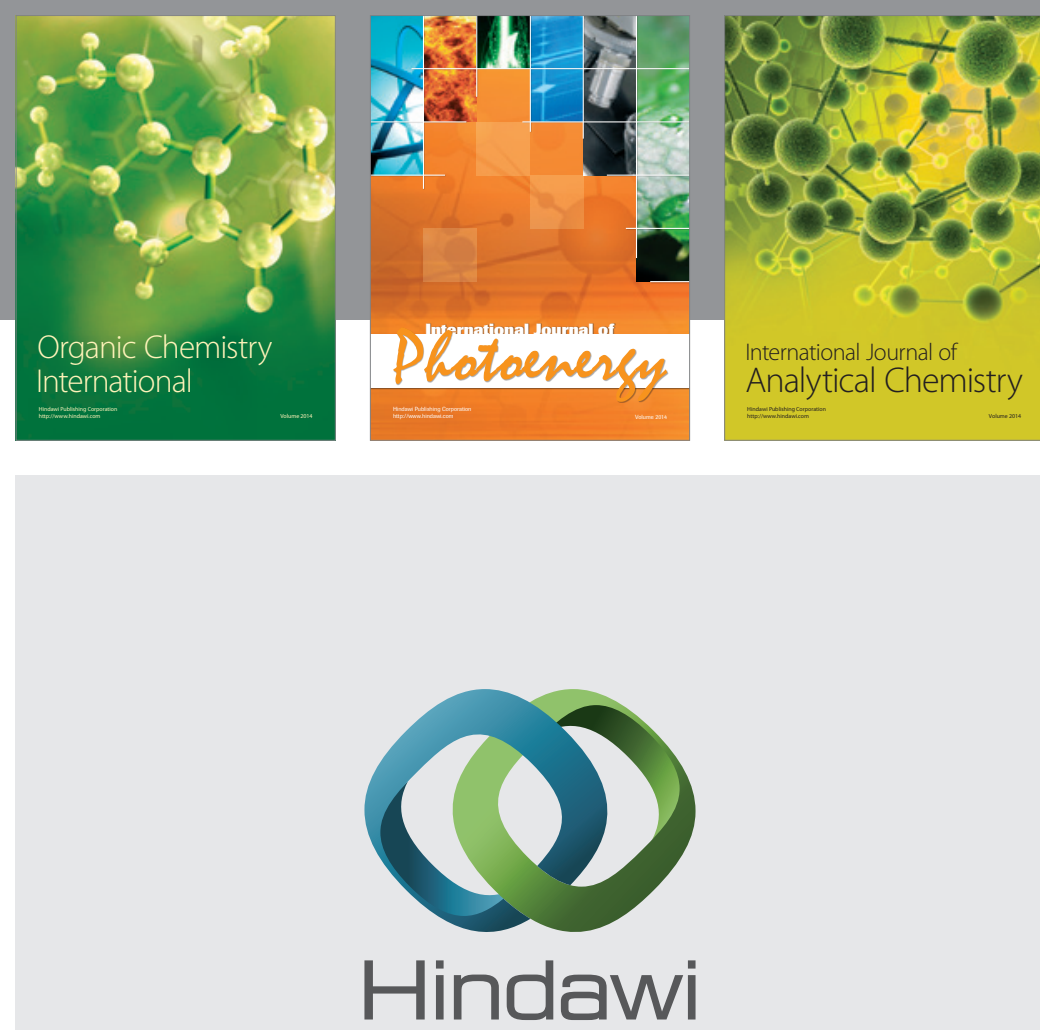

Submit your manuscripts at

http://www.hindawi.com
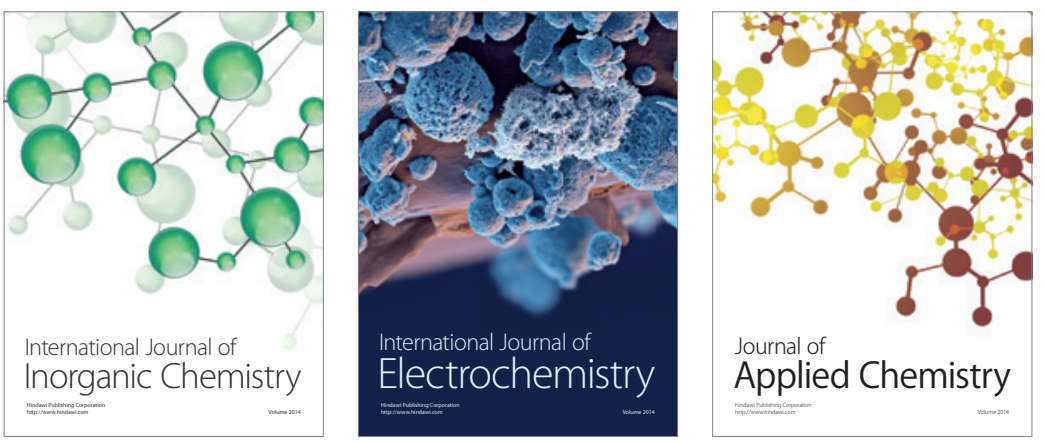

Journal of

Applied Chemistry
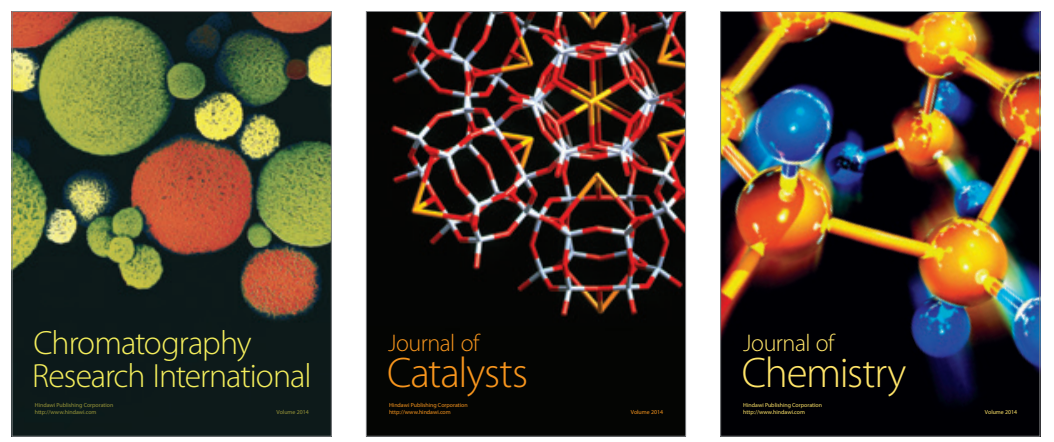
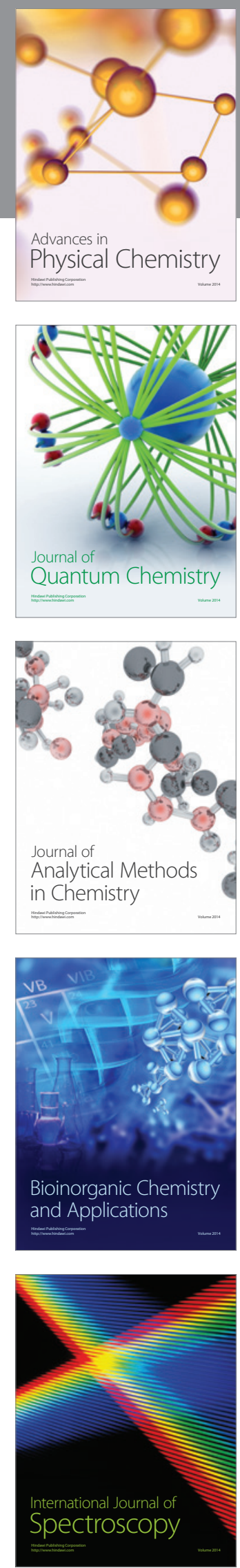